\title{
IT'S A ONCE-IN-A-LIFETIME EXPERIENCE AND OPPORTUNITY- DEAL WITH IT! VOLUNTEER PERCEPTIONS OF THE MANAGEMENT OF THE VOLUNTEER EXPERIENCE AT THE LONDON 2012 OLYMPIC GAMES
}

\author{
KIRSTEN HOLMES,* GEOFF NICHOLS,† AND RITA RALSTON $\ddagger$ \\ *School of Marketing, Curtin University, Perth, Western Australia \\ †School of Management, University of Sheffield, Sheffield, UK \\ ‡Department of Food and Tourism Management, Manchester Metropolitan University, \\ Manchester, UK
}

\begin{abstract}
Mega-events such as the Olympic Games involve huge numbers of volunteers from the host community, necessitating the development of a large volunteer program, which will only operate for a short time. Leveraging this volunteer energy to lead to longer-term community volunteering has become a legacy goal for many event organizers. Mega-events typically use a top-down "program management" approach for their volunteer program. This article examines how the program management style impacts on the volunteer experience, using in-depth interviews with volunteers at the London 2012 Olympic and Paralympic Games. The study found that the program management approach had a negative impact on many volunteers' preevent experience, leading to some rejecting the offer of a role at the event. However, the anticipated "once-in-a-lifetime" experience of volunteering for the Olympic Games overcame most of the preevent shortcomings. The article considers the impact of volunteer management on repeat volunteering. Recommendations for better management of mega-event volunteers, leading to a volunteer legacy, are offered.
\end{abstract}

\section{Key words: Volunteers; Volunteer management; Olympic Games; Program management;} Mega-events

Introduction

This article investigates how the volunteer program management model adopted at the London 2012 Olympic Games affected the volunteers' experiences. The London 2012 Olympic Games provided a unique case study for investigating the experiences of mega-event volunteers for three reasons. Firstly, generating a legacy, including a volunteer legacy, was explicitly stated in both the bid document and legacy plans (Department of Culture, Media \& Sport [DCMS], 2012). Indeed, the London Games were the first Olympic Games to take place under the revised Olympic Charter, 
which required the bidding document to outline legacy plans (Weed, 2012). Secondly, it was the first mega-event to outsource the volunteer recruitment and training to a commercial company (McDonalds) as a form of in-kind sponsorship (Bulley \& Lisle, 2014). Finally, with the official figure of 70,000 Games Makers (the official volunteer program of the London 2012 Olympic Games) recruited, this was the largest mega-event volunteer program to date (DCMS, 2013). This article uses qualitative methods to examine volunteers' experiences both before and after the Games, an approach that has been rarely applied to mega-event volunteers.

The importance of volunteers in the delivery of mega-events has been well documented. The numbers of volunteers required have grown from 40,000 at the Sydney 2000 Olympic Games to the official figure of 70,000 at the 2012 London Olympic Games (Nichols, 2013; Nichols \& Ralston, 2014). Mega-events involve recruiting, training, and managing thousands of volunteers for a one-off, high profile event that will last only a few weeks. As mega-events are typically roaming events, taking place in a different host destination each cycle, the volunteers must be recruited anew for each event. There is some evidence of repeat mega-event volunteers, but these are a small group of individuals (Fairley, Kellett, \& Green, 2007).

The involvement of volunteers in a mega-event has many advantages for event organizers. Firstly, it provides a lower cost temporary workforce; secondly it is an opportunity for the local resident community to become involved in the event. Finally, event organizers and governments claim that these enormous, high profile volunteer programs can lead to a volunteer legacy of increased volunteering within the host destination by trained and experienced volunteers, although there is limited evidence to support this claim, apart from the 2002 Commonwealth Games (Nichols \& Ralston, 2012).

In order to encourage mega-event volunteers to volunteer postevent, their experience needs to be positive. Many factors contribute towards a positive event volunteering experience and the opportunity to be part of a once-in-a-lifetime event is a major motivator for mega-event volunteers (Dickson, Benson, \& Terwiel, 2014). Researchers have more recently recognized that the recruitment and management of event volunteers can significantly affect their experience (Lockstone-Binney, Holmes, Smith, Baum, \& Storer, 2015). Mega-events typically use a "program management” approach (Lockstone et al., 2015; Meijs \& Karr, 2000), which adopts the human resource management practices of paid workers and applies them to volunteers. In the case of the 2012 London Olympic Games, the recruitment and training of volunteers was outsourced to a commercial company, McDonalds (Bulley \& Lisle, 2014), consistent with the governance of the Games through regulatory capitalism (Nichols \& Ralston, 2015). The governance structure involved the UK government awarding a contract to deliver the 2012 Games to the London Organizing Committee for the Olympic Games (LOCOG); who, as a private-sector umbrella organization, awarded over 75,000 (sub) contracts to private companies (Girginov, 2012). Significantly, LOCOG had no responsibility for legacy, its role was just delivery (Lockstone-Binney, Holmes, Smith, \& Shipway, 2016).

Although the 2012 London Olympic Games were the first Games to take place under the revised Olympic Charter, requiring legacy plans to be provided in the bid document, these legacy plans were far from clear (Weed, 2012). "Volunteer legacy" was mentioned but not articulated other than as an intention to get more people volunteering as a result of the event (DCMS, 2012). How this would be achieved, and who would be responsible was not clear (Nichols \& Ralston, 2012).

This article investigates how the management practices at the London 2012 Olympic Games affected the volunteer experience by examining the volunteers' perceptions and identifies the implications for a volunteer legacy.

\section{Literature Review}

The literature on event volunteering has increased substantially over the past 20 years (Smith, Baum, Holmes, \& Lockstone-Binney, 2014). The dominant theme among research specifically on megaevent volunteers, including Olympic Games, has been their motivation (Dickson et al., 2014; Fairley et al., 2007; Giannoulakis, Wang, \& Gray, 2008; Koutrou \& Pappous, 2016), particularly as a means to provide insights into volunteer recruitment and retention for future events. Studies have noted that there are specific motivators for mega-event 
volunteers including the opportunity to be part of a "once-in-a-lifetime" experience (Dickson et al., 2014), and pride in their home destination (Kim, Kim, \& Odio, 2008). Interest has also grown in how mega-event volunteering can lead to a volunteer legacy for the host destination (Auld, Cuskelly, \& Harrington, 2009; Doherty, 2009; Koutrou \& Pappous, 2016; Nichols \& Ralston, 2012). However, there have been few studies that examine how the management of mega-event volunteers can affect their experience and subsequent likelihood to volunteer at future events.

This review first examines current research on event volunteer management models and how these affect the volunteers' experiences leading to satisfaction or dissatisfaction. Next, a review of the methods used to investigate event volunteers is considered, and finally, research on volunteer legacies is presented.

\section{Models for Managing a Mega-Event Volunteer Program}

Event organizations can approach the management of volunteers in different ways (Smith \& Lockstone, 2009). The dominant volunteer management approach used by events is the "program management" model, whereby volunteers are recruited and assigned to roles, which meet the needs of the program, rather than trying to meet the needs of the volunteers (Meijs \& Hoogstad, 2001; Meijs \& Karr, 2004). This is the model used by most mega-events and seeks to replicate the human resource management practices used for paid staff with a volunteer workforce (Cuskelly, Hoye, \& Auld, 2006).

The program management model is typically adopted as the most efficient way of recruiting, training, and managing the enormous number of volunteers needed for the short time required for a mega-event (Lockstone \& Baum, 2009). Its focus is on recruiting volunteers for the tasks that need to be completed. However, the approach has been critiqued as inflexible, indeed even draconian, and focused on the needs of the event organizers at the expense of the volunteers (Lockstone \& Baum, 2009). A review of the volunteer program at the Melbourne Commonwealth Games, which used the program management approach, found that volunteers were initially excited about getting accepted and experienced postevent euphoria but their experience during the event was more negative (Lockstone \& Baum, 2009). In particular, the rigid application of the program management approach contributed to this more negative experience. For example, it was not possible for volunteers to change the role they had been allocated, in part due to the logistics of organizing such a large group of volunteers, and nonattendance at training would result in a volunteer losing their role at the event. The volunteers were expected to be available for the whole event period and some volunteers were allocated such grueling schedules that they quit, with a drop-out rate of 1 in 10 . There was a sense that as there were so many volunteers, they were treated as being expendable (Lockstone \& Baum, 2009).

The Manchester Commonwealth Games also used a program management approach, which was evaluated before the event (Ralston, Downward, \& Lumsdon, 2004). The large-scale orientation event held for all volunteers was viewed with mixed feelings. Volunteers felt that jobs had been allocated seemingly at random and did not take into account the skills and experience that they had been asked about during recruitment. However, there was good communication between the event organizers and the volunteers, which made the volunteers feel special. Ralston et al. (2004) noted that the volunteers in their sample expected to be managed and valued from the moment they submitted their application form given the commitment they were making to the event, often taking their annual leave to volunteer.

Other Olympic Games organizers have modified the program management approach. At the 2000 Sydney Olympic Games, a pyramid method was used. An initial group of 500 "pioneer volunteers” were recruited first (Fairley, Green, O’Brien, \& Chalip, 2015), who then promoted the volunteer program nationally to potential volunteers for the much larger group of 46,967 GamesForce 2000 volunteers, who were subsequently recruited (Lockstone-Binney et al., 2016). Specialist volunteers were also recruited separately at Sydney so that recruitment and training were staggered. Some mega-events have also used targeted recruitment in their application of program management. The 
2000 Beijing Olympic Games targeted one specific group in their volunteer recruitment-students (Zhuang \& Girginov, 2012).

An alternative model for event volunteer programs is the "membership management" approach, which focuses on meeting the volunteers' expectations and matching the necessary tasks for the event to these (Meijs \& Karr, 2004). It is about finding roles and tasks that suit the available volunteers, often tailoring a particular role to an individual. A program management model is more common for organizations that involve paid staff while a membership management model is more suited to an allvolunteer organization and small local events and is generally more work intensive for the volunteers (Meijs \& Karr, 2004). Clearly any one event will have a balance between the two approaches, but it is our contention that London 2012 was an extreme form of program management, with consequences for the volunteer experience.

The literature suggests the way in which volunteers are managed can have a positive or negative impact on their motivation and subsequently their retention. In particular, volunteers report that they want their time and efforts to be managed well (Musick \& Wilson, 2008), with one of the most common drawbacks of volunteering reported as "things could be better organized” (Low, Butt, Ellis Paine, \& Davis Smith, 2007). Although there is limited research on volunteers' satisfaction with managerial treatment in the events context, it has been identified as having a positive influence on their intention to continue to volunteer (Kim, Chelladurai, \& Trail, 2007) and when this is not the case, volunteers withdraw their services (Hager \& Brudney, 2004).

Researchers have suggested that because the volunteer workforce at an event is unpaid and temporary, limited attention is paid to the management of the volunteers (Cuskelly et al., 2006). This is evident even at some mega-events, which involve a huge number of volunteers. For example, Kodama, Doherty, and Popovic (2013) reported on the limited and ambiguous instructions given as a volunteer at the Vancouver Winter Olympics. Poor management can have a negative effect on the volunteers' sense of pride of being involved in the event (Kim et al., 2008).

Previous research has identified the importance of training prior to the event as a way of bringing a group of volunteers together, creating a sense of community before the event, which will enhance the volunteers experience during the event and the support they feel they receive from other volunteers (Costa, Chalip, Green, \& Simes, 2006). Another factor that impacts on the volunteer experience is having a "good" supportive supervisor (Coyne \& Coyne, 2001). Good job design strongly influences volunteer satisfaction (Neufeind, Gunter, \& Werner, 2013), which has a positive impact on volunteers' future intention to volunteer (Wang \& Yu, 2014). Although research shows that event volunteers, as occasional, episodic volunteers, value flexibility in the organization of their time (Smith \& LockstoneBinney, 2009), mega-events are known to be demanding for the volunteers both before and during the event, and to operate with strict, inflexible guidelines (Lockstone \& Baum, 2009).

In summary, there is limited research on how the type of management approach used at a megaevent affects the experience of the volunteers. Most research on this topic has been quantitative and has typically involved surveying the volunteers at a specific time during the event cycle, either after the event or at the event itself (Johnston, Twynam, \& Farrell, 1999; Koutrou \& Pappous, 2016; Lockstone-Binney, Holmes, Baum, \& Smith, 2014; Neufeind et al., 2013), as this is when it is easier to access volunteers. Few articles have surveyed the volunteers at multiple stages (Ralston, Lumsdon, \& Downward, 2005; Smith, Wolf \& Lockstone-Binney, 2014). Although the quantitative approach identifies relationships between variables such as training and volunteer satisfaction, this provides limited insight into how different approaches affect the experience. Only a few qualitative studies have explored the event volunteer experience in depth (Kodama, Doherty, \& Popovic, 2013; Tomazos, \& Luke, 2015; Wilks, 2015). These have not examined how the type of management approach affects the volunteers and the possible implications for subsequent volunteering as part of a volunteer legacy.

\section{Creating an Event Volunteer Legacy}

Researchers have investigated event volunteer commitment and how to encourage repeat volunteering (Costa et al., 2006; Elstad, 2003). In the context of mega-events, this theme seeks to understand 
how an event volunteer program can lead to future volunteering in the host destination as part of a social or community legacy (Auld et al., 2009; Doherty, 2009). The primary example of a successful event volunteer legacy is Manchester Event Volunteers (MEV), a broker service, which was set up following the 2002 Commonwealth Games to connect event organizers and potential volunteers in the Greater Manchester area (Nichols \& Ralston, 2011). This was successful partly because structures were in place to channel the enthusiasm, postGames euphoria and regional pride of volunteers into further opportunities. MEV is still operating in a very limited form as government funding has been greatly reduced since 2010 (Holmes, Hughes, Mair, \& Carlsen, 2015). Creating a volunteer legacy was claimed to be an aim of the London 2012 Olympics, with the Deputy Prime Minister, Nick Clegg, stating: “At London 2012, we're looking not only to celebrate this Olympic spirit, but use it to get more people volunteering in future" (DCMS, 2012, p. 51). However, the governance of the Games through regulatory capitalism led to a split of responsibilities between delivery and legacy in which LOCOG had no remit to support or deliver a volunteer legacy strategy (Nichols \& Ralston, 2015).

This article brings the themes of event volunteer management and legacy together by investigating how far the management approach and management practices at the London 2012 Olympic Games affected the experiences of the volunteers, and the subsequent implications for a volunteer legacy.

\section{The London 2012 Games Maker Program}

This study is of Games Makers, the term used to describe the volunteers recruited by LOCOG to support the 2012 Olympic Games. A description of the process of application, interview, selection, and training is essential for understanding the experiences of our interviewees. The scale of the volunteer program was huge. A total of 240,000 people applied to be Olympic volunteers, from whom 100,000 were selected for interview in London and eight regional centers between February 2011 and March 2012, up to 16 months after submitting their initial application. It took up to 18 months for most interviewees to be informed if they were successful although for many, the period postinterview until notification of outcome was much shorter (Nichols, 2013; Nichols \& Ralston, 2014).

Successful applicants were required to attend two training events in London, including an initial orientation session, and a third at their Olympic venue (usually in London). They might also be required to attend test events in the summer of 2012 and also had to make an additional visit to London to pick up their accreditation and uniform, even if they were volunteering at a venue outside of London. There was no support provided for travel at any stage or any assistance with arranging accommodation in London. Volunteers were notified of their scheduled shifts from May 2012 onwards.

Although LOCOG was responsible for delivering the Games and managing the volunteers during the event, McDonalds designed the training materials, interview, and selection process, although interviewing of applicants was conducted by a group of volunteers and students who had applied specifically to be Games Maker interviewers. This contrasts with previous mega-events. For example, at the Manchester Commonwealth Games the local organizing committee directly recruited volunteers with involvement from the voluntary sector (Downward \& Ralston, 2006) and at the Beijing Olympics university students were specifically targeted by the local organizing committee (Zhuang \& Girginov, 2012).

\section{Method}

In order to fully explore the experiences of London 2012 volunteers, a qualitative approach was adopted in this study. Research on the different management models of event volunteers is limited, thereby requiring an exploratory approach. Although previous quantitative studies have identified a number of factors that can affect the volunteer experience, it is not clear how they do so, indicating that a more in-depth approach would be valuable. The few studies, which have used a qualitative approach to investigate mega-event volunteering (Ralston et al., 2004; Kodama et al., 2013; Tomazos \& Luke, 2015), demonstrate the value of in-depth investigation into the volunteer experience. Indeed, Musick and Wilson (2007), in their seminal book on volunteers, argue that any 
attempt to understand volunteerism needs to take into account the social context within which it takes place, again pointing to a qualitative approach. A small number of studies have examined how the event volunteering experience has met volunteers' expectations by exploring these prior to the event (Tomazos \& Luke, 2015) and then evaluating the volunteers' experiences during and/or after the event (Kodama et al., 2013; Neufeind et al., 2013; Ralston et al., 2004; Smith et al., 2014). This would seem necessary to evaluate both the volunteer program and the likelihood of an individual continuing to volunteer after the Olympic Games.

For this project, data were collected in two stages both before and after the event. Before the Games, face-to-face semistructured interviews were conducted between February and June 2012 with individuals who had volunteered for the Games. By this time the participants had experience of application, interview, being offered a role, orientation training, role and venue training, notification of shifts, and possibly attending test events; although not all interviewees had completed all these stages and only a few had attended test events.

Participants were purposefully selected for the interviews. Participants were initially sampled through an e-mail request to members of Manchester Event Volunteers, a volunteer events broker organization established after the 2002 Commonwealth Games, which is cited above as the only example of a successful volunteer legacy. This provided an initial sample, which was expanded through "snowballing" whereby the initial interviewees were asked to recommend further participants who met the eligibility criteria for being included in the study (Cresswell, 2013). The only sampling criterion was that participants had been selected to volunteer at the London 2012 Olympic and Paralympic Games. A total of 53 participants were interviewed in this first stage, by which theoretical saturation had been reached and no further new insights were being generated by the interviews (Guest, Bunce, \& Johnson, 2006).

By the time of the initial research interview, 13 of the 53 participants had withdrawn from the Games Maker recruitment process, providing a valuable perspective on reasons for withdrawal. The interviews followed a simple chronological schedule, asking volunteers to describe the stages of their recruitment and training and how these affected their motivation. The interviews varied between 20 and 90 minutes in length, allowing volunteers ample time to contextualize their experiences. We note that the participants were untypical geographically as Olympic volunteers in that they predominantly came from the Manchester and Sheffield areas, both approximately 200 miles north of London. Only 4\% of all Games Makers came from the North West, and 4\% from Yorkshire and the Humber (Dickson et al., 2014), the regions of the UK in which the cities of Manchester and Sheffield are located respectively, while 34\% came from London. Thus, our sample had greater travel costs and was more likely to have to arrange their own accommodation in London, at their own expense. We note this as a potential bias in our analysis of the data.

Stage 2 of the fieldwork involved a series of four focus groups, which were conducted post-Games with the same sample. All interviewees from the original sample who accepted roles at the Games were contacted and asked to participate in the focus groups. From the 40 pre-Games interviewees who went on to volunteer at the Games, 19 agreed to participate in the focus groups. The focus groups were held between 6 and 10 weeks after the Games. Selection reflected those available for interview at the times the groups were held. Focus groups were preferred to individual interviews because the interaction between volunteers would better reflect their collective experience (Morgan, 1997). The focus groups used a very open schedule, which asked each participant to describe the high and low points of their experience as a Games Maker, their views on the way they were managed, and how volunteering at the Games might affect their future volunteering intentions. The post-Games focus groups were facilitated by two researchers: one to act as a moderator and one to intervene to follow-up insightful comments (Krueger \& Casey, 2000). Following the focus groups, the researchers wrote summary notes, and all interviews and focus groups were recorded and transcribed verbatim for analysis.

Both the interviews and the focus groups were analyzed thematically with the support of NVivo 11. The method of analysis used the typical approach for qualitative research. This involved reading and rereading the interview transcripts, the development of a coding template, that included 
broad categories identified in the literature (motivations, training, recruitment), and data were then analyzed inductively within each category, with themes allowed to emerge from the data. The data were all initially coded by one researcher from the team and then code checked by a second researcher for consistency (Miles \& Huberman, 1994). The quotations provided in this article have been anonymized. It was not possible to interview LOCOG staff as consistent with the governance structure of the Games, as this would have necessitated signing a nondisclosure agreement which might have prevented open academic commentary (Nichols \& Ralston, 2015).

\section{Findings}

The findings are organized chronologically, with the themes linking to the different stages of the volunteer recruitment, training, and management process (Holmes \& Smith, 2009). This approach is designed to aid understanding of how the management style affected the volunteers' experience at the London 2012 Olympics and Paralympic Games. The findings begin by outlining the volunteers' motivation to become Olympic volunteers. This is followed by recruitment and training; the experience at the Games; rewards received by the volunteers from volunteering; and evaluation of the volunteer program.

\section{Motivation to Volunteer at the London 2012 Olympic Games}

The interview participants were highly motivated to volunteer at the 2012 London Olympic Games. Many cited their motivation as the opportunity to be involved in a once in a life time opportunity: "I don't think there will be another Olympic Games in this country in my lifetime and this was a great way to get involved" (Karen).

For others, specifically the students in the sample, this was seen as a valuable experience to add to their CVs. This was the case for students studying related subjects such as Event Management but also for others doing unrelated programs. A number of participants had been involved in previous mega-events, which had encouraged them to repeat their experience. These included the 2006
Commonwealth Games in Manchester and also the 1991 World Student Games in Sheffield:

I had such a good experience in the World Student Games in 1991. I had a month off work, I was seconded. I had a free month and I said to them what do you want and I was actually working with (named removed) managing the volunteers who looked after the dignitaries which in hindsight wasn't really what I wanted to do but I was also based in the hotel looking after the medical team which was fun. (Mary)

Eighteen participants had volunteered at events through MEV (Nichols \& Ralston, 2012). This meant that these participants were experienced event volunteers, often with high level expertise in a specific sport. The strength of each individual's motivation was such that they were willing to bare substantial costs and other sacrifices in order to be involved in the Olympic Games. One student commented that she chose to miss exams in order to attend a training session:

I was oohing and aahing about whether I should $<$ attend the mandatory training > because it was obviously during term time and I was like should I do it, exams would be soon afterwards . . . and then I finally decided “yes let's do it” because I am in first year, my year doesn't really matter, this is not going to happen again. (Chloe)

\section{Recruitment and Training of Volunteers}

The recruitment and training process is outlined above. This section reports participants' experiences of this process. The online application form was considered relatively straightforward to complete, although some experienced volunteers felt that there was insufficient room for them to include all their skills and knowledge. Individuals who were involved with a specific sport club were given a code to enter into the application form, which would link their application to that sport.

A limitation of the application form was that only individual applications could be submitted. Couples, families, or friends wishing to volunteer together could not apply together, which led to problems later on with the roles, locations, and shifts that they were allocated. Given that couples and families would want to share accommodation during the event, being at different locations would 
be problematic. One participant contacted LOCOG regarding this problem and received the following response: “Thank you for contacting London 2012 about your Games Maker role. Unfortunately, we are unable to assign the same roles for you and your husband as we have 70,000 applicants to be assigned to the various roles" (E-mail received by Brenda).

The interviews were all conducted at centers around the country, which made it easier for participants to get to than if they had been in London. The interviews themselves were standardized and undertaken by seemingly inexperienced volunteers:

"Well she [the interviewer] was very inexperienced, very slow, misunderstood what I said sometimes and . . . when it got to a sort of buzzer bell to say have you nearly finished she was four questions off the end and she stopped” (Mary).

These left participants confused as to how the interview would enable LOCOG to match them to a role appropriate to their skills and experience. The interviewers were also unable to answer any questions about the volunteer program. A volunteer described a friend:

He's got masses of experience and all they did was stuck him on a road crossing in Leatherhead ... he was a Major in the Army. His organizational skills, his knowledge of sport, his management of both volunteers and staff was just phenomenal and they just weren’t using him. (Karen)

Successful interviewees had to attend an orientation event in London. Participants had mixed views about the orientation. This involved showing a number of videos emphasizing the importance of the volunteers; however, it was noted that they still had to pay for their own refreshments. Some participants commented that the orientation made them feel excited about being involved in the Olympics, that it made it feel "real" to them, but also that it was superficial. One experienced event volunteer said:

Well the orientation was very well put together, very professionally managed but it was a lot of "fluff" to be quite frank but then what could you do if you are sitting 12,000 people in an Arena? To be brutally honest . . . I was stood in the queue for the toilets afterwards and a woman said they could have sent out the pack and put a clip on YouTube and that would have been a lot easier for all of us and she had got a point. (Karen)

Next, participants had to attend a number of training events, which were found to be of varying usefulness:

Training . . . was a very general talk of how we should act and how we should kind of behave and not, it was a very general talk, nothing at all to do with what any of us were doing yet none of us knew what we were doing at the end of the talk. (Chloe)

All training took place in London or at Olympic venues and was separated from collecting uniforms, which involved an additional trip to the Londonbased uniform depot, leading to extra transport costs for potential volunteers.

The recruitment and training process had begun very formally but as it got closer to the actual event, this became more informal, including the use of telephone interviews. One participant suggested this was because so many people were dropping out of the recruitment process or turning down offers that there was a sudden need to recruit more volunteers.

Among our participants there were mixed reactions to the training. Some participants felt that the whole standardized process was inappropriate to a volunteer program, while others liked the professionalism that the standardized process presented to them. However, the problems with communication between LOCOG and the participants and the delays in providing information, along with sending out contradictory messages left a poor impression:

\footnotetext{
"It was slick and very well done and it was all geared up to making you feel that you were important to the Games, but they haven't unfortunately followed that through since” (Jodie).
}

The messages that were presented to volunteers as part of the recruitment and training process were contrasted with the reality they experienced:

Volunteering is about having fun and meeting people and looking after the visitors who come into the event. Yeah, it's about working hard too but I just felt the Olympics didn't see things from a volunteer's point of view. I didn't get the 
impression of any flexibility. It was a question of "this is what we want from you-take it or leave it.” I just didn't think they cared enough about the volunteers to look after us properly. (Lauren, who declined the offer of a volunteer role)

\section{Role and Shift Allocation}

A problem for participants throughout the process leading up to the event was communication with LOCOG. This was all done via e-mail, with many standardized messages, thereby requiring all volunteers to have regular internet access and specific computing facilities:

So first of all, I couldn't access my shift rota. There is something on your Games Maker, you know, this page which tells you your status and stuff like that, well it says "view shifts" so I click "view shifts" and nothing happens. ... In the end I phoned the number and said this is ridiculous ... and [I was told] it doesn't work on Apple Macs. (Mary)

The communication was just one part of a process that treated volunteers as numbers rather than as individuals. This seemed very obvious to participants when they were allocated their shifts:

I mean these shifts to me look like they've been done by a computer, not a person, nobody has sat down and said we will give this 66 year old 5.15am shifts. ... I'm very active and I can get up at 3.00 in the morning, it's just that waste of 2 hours in the middle of the night that has pushed me over the edge. I am not being unreasonable. (Mary)

Some participants contacted LOCOG directly and found that staff were very helpful. For example, after receiving the e-mail from LOCOG saying that he could not volunteer with his wife, Brenda's husband contacted LOCOG directly and threatened to withdraw if they could not volunteer together:

It's not a case of whether I would do the shifts or whether we can negotiate, it's a question of whether I will do anything at all. This is conditional upon my wife getting the same shifts and working in the same area. (Brenda's husband)

They were then reallocated to the same team at the same venue.

Another participant did not like the role they had been allocated-a driver for VIPs at a hotel in
London - and so telephoned LOCOG to request a change of role and was reallocated a role as a medal bearer:

So I gave them a call and said I've been given this role, I didn't really know that's what I was going to be given, I could do it at a push but if there is something different I can be transferred to there is probably something I would be better suited to ... . and then there was probably a month gap and then I got an email saying that I was to be a part of the medal and garland bearer team. (Darren)

Clearly, it paid to complain directly to LOCOG.

\section{The Experience of Volunteering at the Olympic Games}

In spite of all the negativity among participants in the preevent interviews, the post-Games focus groups identified "this tsunami of positivity" (Manchester focus group 1) from participants about their experiences at this once-in-a-lifetime opportunity. The participants were still experiencing Olympic euphoria at the time of the focus groups. Much of this euphoria was due to the very positive attitude of the public towards the volunteers:

I think it was after the first couple of days where all the volunteers were still quite bouncy and happy so I wasn't the only one still dancing anymore and ... just having the public go up to us and say "you're really great" so the people genuinely really liked us being there and being happy and so many athletes and celebrities were saying the volunteers are really good. (Sheffield focus group 1)

The distinctive uniform of the volunteers really helped in creating a sense of identity and meant that everyone could recognize that they were volunteers and part of the Olympic Games. Indeed, we recruited one focus group participant after we saw them sitting in a pub wearing their uniform a number of weeks after the event. When we approached him, we discovered that he was one of our original interviewees. A further reason for this euphoria was the success of Team GB and one participant commented about the management of the volunteer program:

They could have been the worst managers in the World it wouldn't have made any difference, we 
would have still been positive about it because it didn't matter that the feelings you were getting from everything else just washed it out the water. (Manchester focus group 2)

It is important to remember that volunteering at the London Olympics really was hard work. Volunteers had to complete long shifts and were often on their feet all day:

We worked 12-hour shifts which would invariably end up 14-hour shifts, and you start at 5.30 in the morning and you hadn't been to the toilet by 2.30 or 3.00 in the afternoon and you just hadn't sat down because of all the problems coming into the depot. (Manchester focus group 1)

This was in addition to the costs involved, particularly with accommodation and that many people were volunteering during their annual leave. However, the reality was much more flexible than the preevent training and communication suggested, and this flexibility depended on the volunteer team leader:

Ours were pretty flexible. They asked where we were living and what time our last train was, and they had a print-out of the last trains going from Stratford and some people did have to leave early and it was fine we had enough people on the shift to cover if we needed to. (Manchester focus group 2)

\section{Recognition and Reward of Volunteers}

Rewards offered were material and included discounts in various shops, free public transport in London during shifts, thank you letters from the Chair of LOCOG and the British Prime Minister, a souvenir baton, along with being provided with their uniform and lunch during shifts. A downside was that there was no official "end of Olympic Games" thank you event for the volunteers. Some volunteers organized their own "thank you" for their team members:

Can I just say this was where I got the long straw and not the short straw because every person that left on their last shift we had a group photograph of them going so they could have a photograph of them with the team that was on duty that day. And the last day was the last day of everything. And I think it probably did make a difference if you stayed until the end and our team buddied up with the catering team and we had fizz and pizza. (Sheffield focus group 2)

For others: "At the end? We just finished our shift and then we left" (Sheffield focus group 2), an anticlimax of a volunteer experience.

\section{Evaluating the Volunteers'Experience}

In spite of their euphoric experiences at the Olympic Games, volunteers could still remember the problems they had before the event. The whole recruitment and training process "did feel a little bit like an assault course if you got through that then that was part of the test" (Sheffield focus group 2).

It is not possible to say how many potential volunteers dropped out of the program before the event, as did 13 out of our sample of 53, and how far they have been deterred from any future volunteering.

Having participated in the volunteer program, the focus group participants made a number of recommendations for improving the process. Firstly, they suggested recruiting the team leaders first and then involving them in the subsequent recruitment of their teams:

The recruitment should have been in a pyramid so that you recruited the team leaders first, I think, and then maybe get them recruiting. To have those McDonalds girls and I don't mean to be disrespectful to them but to have them interviewing at that level and to make those decisions was probably not the most effective way of doing it. (Manchester focus group 1)

Many volunteers felt that people's skills were not being matched to the role they were eventually assigned during the recruitment process. It was very likely that this match was not made by the interview process as the interview questions were too standardized, general, and the interviewees unskilled. One example given was of volunteer drivers who had no experience of driving with a manual gear box or on the left-hand side of the road (in the UK).

In addition, the training was criticized as not equipping people to do their assigned role. For example, the volunteers at the Olympic Park were simply walked round the park during their training 
and did not get the chance to practice the kinds of queries they would be dealing with. As the maps of the Olympic Park did not have toilets or refreshments marked on, the volunteers had to locate these themselves on their first day and add them to their maps.

Many of the participants felt that the volunteer program was not well organized and this was particularly apparent on the first day. Some participants felt underused during the event. This was due to a number of factors. Firstly, the same number of volunteers in each role were allocated to all venues, so this led to a team of 10 being allocated to processing results at one venue when most of the time only one or two were needed. Another example was drivers being allocated to VIPs who did not need driving anywhere. "because we weren't doing very much all the time the competition was on it only needed one person so the rest of the time we were just wandering about" (Manchester focus group 2). Additionally, many volunteers from the morning shift chose not to leave after their shift, so there was competition with the afternoon shift over roles.

Finally, participants commented how not all volunteer roles were equal. Although some participants were involved in handing out medals, meeting the athletes and VIPs at the venues, others might be remote from the events to the extent that they did not know results of key competitions. There was a feeling that people should only be asked to volunteer for "interesting jobs" such as driving athletes, assisting at venues, rather than checking passes in a corridor:

\footnotetext{
There were people I walked past everyday whose role was to sit in a corridor and they would just sit in a corridor and check the badges. I kind of think it was a bit cheeky what people got asked to do under the name of volunteering. There was a lot of free labour going round to be honest and asking people to get to work for like 5am and stuff like that I thought was a bit cheeky. (Sheffield focus group 1)
}

Overall, at least up to the event, several volunteers expressed the view that LOCOG were exploiting their market position:

They treat you like you are literally a herd of whatever and the biggest feeling I get is as soon as you say I am not very happy with that they will say "you are one of 70,000 and there were 250,000 applied, if you don't like it there is other people behind you." It was if you read the bumph that they send out it says things like "without you as volunteers we cannot run this Olympic Games" but quite frankly from LOCOG I'm not feeling like I'm valued. (Karen)

\section{Discussion}

The findings from the interviews and focus groups reveal the challenge of managing a megaevent volunteer program on the scale of the London 2012 Olympic Games, possibly the largest temporary volunteer program ever created. LOCOG set themselves an additional challenge by electing to recruit all the volunteers at the same time and also to build a diverse volunteer cohort, extending the experience to people from across the country (although they did not achieve the latter). Previous Olympic Games have staggered their recruitment, as at Sydney (Lockstone-Binney et al., 2016), or focused on one source market, frequently university students, as in Beijing (Zhuang \& Girginov, 2012).

The volunteers in our sample were highly motivated and excited to be selected for the London Olympic Games. They talked about it being a "oncein-a-lifetime" experience and this initial excitement is common at high profile mega-events such as the Olympics (Dickson et al., 2014; Lockstone \& Baum, 2009; Ralston et al., 2004). However, this motivation began to wane as the volunteers went through the recruitment and training process.

Recruiting such a large number of people all at once led to the adoption of the program management approach with a very rigid, standardized system, found at other mega-events (Lockstone \& Baum, 2009). This worked well for some of our participants, but did not take into account individual needs, particularly the need for people to be able to volunteer together. This was a practical need as individuals from outside London needed to arrange accommodation together. This lack of an individual approach was implemented by outsourcing the recruitment to a commercial organization with little experience of volunteer management, regardless of how much input McDonalds had into this process. This was symptomatic of the "take it or leave it" approach found at similar mega-events, where there is a sense that will be plenty more 
volunteers if someone drops out of the process (Lockstone \& Baum, 2009).

This sense was evident in various stages of the recruitment and training process. For example, many participants commented on how at the orientation event they were bombarded with messages about how important they were as volunteers and yet they were not important enough to get a free cup of tea or refreshments at the event; which was being run by McDonalds! The message to volunteers needs to be consistent. Volunteers also objected to the insincerity of mass communications, such as the one confirming their role postinterview: "Electing the volunteers was a tough job but we were really impressed with your interview. We know you've got the passion and enthusiasm.” As one participant commented: these were "just words and I don't believe them" (Boris).

There was considerable variation in the roles that volunteers were allocated. Roles seemed to be allocated randomly, with little apparent consideration for the volunteers' skills and experience, which had been elicited during recruitment and selection. This randomness is a feature of the program management approach at mega-events (Ralston et al., 2004). Clearly some roles are more exciting and coveted than others and it is unlikely that any mega-event volunteer program will be able to match everyone to the role they want. However, event organizers could acknowledge where volunteers do not get their first choice and perhaps offer something in addition for those doing the less enjoyable or furtherfrom-the-action roles.

Although LOCOG presented a standardized, inflexible approach towards the volunteers, some of our participants found that when they contacted LOCOG directly, they were able to obtain the outcomes they wanted. It seems that the program management approach was used for all volunteers, but those willing to put time into complaining received a more membership management-oriented approach (Meijs \& Hoogstad, 2001), with more consideration given to their specific needs and skills. Possibly by this time LOCOG realized they needed to do this to ensure the required number of volunteers. This is suggested by the fact that some potential Games Makers were still being recruited by LOCOG as late as June 2012. Possibly LOCOG reviewed its program management/membership management balance according to the balance of supply and demand for volunteers. Thus, not all volunteers were treated equally.

Training was found to be of mixed benefit. In spite of attendance at training sessions being mandatory, similar to other mega-events (Lockstone \& Baum, 2009), it did not necessarily prepare the volunteers for the actual role they would be performing. Kodama et al.'s (2013) account of volunteering at the 2010 Vancouver Olympic Games reported the same problem. The main reward for the volunteers was being a part of the Olympic Games. Many volunteers were also able to meet athletes and other VIPs. Material rewards were a nice addition, along with the various thank-you letters, but previous research has found that material rewards are the least important motivations for event volunteers (Williams, Dossa \& Tompkins, 1995).

However, the outcome was that despite all the problems experienced by volunteers before and during the Olympic Games, they generally enjoyed being able to participate in the event. Therefore, the risk for losing volunteers and potentially damaging the volunteer legacy of the event was mainly during the recruitment and training before the event. The importance of training in motivating event volunteers has been previously noted (Costa et al., 2006), alongside flexibility and a good supervisor (Coyne \& Coyne, 2001) and the findings in this study reinforce this. The lack of flexibility throughout the recruitment and training process was commented on repeatedly. In contrast, individual supervisors facilitated considerable flexibility at the event itself. The positive start and finish with a more negative experience for the volunteers in between has been noted at previous megaevents (Lockstone \& Baum, 2009; Ralston et al., 2004). Although the positive end note is good news for volunteer legacy planning, the risk is with those volunteers who drop out during the negative middle phase. It is possible that their negative experience before the event will reduce their likelihood of participating in any form of volunteering in the future.

The limitations of the selection process interviewers, who were found by our participants to be inexperienced, unable to deviate from their script, or answer questions might have been if a pyramid approach, similar to that used at the 2000 Sydney Olympic Games (Fairley et al., 2015) and described by one of our participants was employed. 
This would involve recruiting volunteers in stages and involving the earlier recruited volunteers in the subsequent recruitment of the larger volunteer cohort. Recruiting the volunteers in stages would help manage the recruitment process and enable trained volunteers to be involved in the next stages of recruitment. This approach would also enable volunteers to be recruited, trained, and managed in smaller units. This could be more personal, flexible, and enable individuals' skills and experience to be matched to specific roles where possible.

\section{Conclusions}

The complexity of the London 2012 Olympic Games, the size of the volunteer program, and the political capital invested in successful delivery on time inevitably led to the adoption of a program management approach. This dominated during recruitment, training, and allocation of roles; although shortly before the Games and during them, there were more indications of membership management. We have identified where this could have been extended; for example, by role rotation. The management style led to some volunteers withdrawing before the Games: in our sample this applied to 13 out of 53 but we are unable to extrapolate from this the overall loss of potential volunteers. Not only were potential volunteers lost but many of our interviewees had applied to volunteer at the London 2012 Olympic Games because of positive experiences at previous large events such as the Manchester Commonwealth Games.

It is clearly important to treat volunteers well throughout the event planning and delivery process in order to encourage future volunteering postevent leading to a volunteer legacy. The program management approach led to some negative perceptions afterwards, which may also have affected further volunteering. However, LOCOG's contract was just to deliver the Games, not to also generate a legacy. This contract made LOCOG's work simpler, cheaper, and reduced political interventions. LOCOG's ability to use this version of program management was made possible by the very strong motivations of volunteers to be part of a "once-ina-lifetime" experience.

Practical implications for event volunteer managers are that an inflexible program management approach was not popular with volunteers, as it did not take into account personal circumstances, with the result that some volunteers withdrew. In less prestigious events this extreme program management approach will not be practical in retaining volunteers' commitment. An alternative method of recruitment would be a pyramid approach, as used at the Sydney 2000 Olympic Games, which offers a way to engage a large number of volunteers in a more personal manner and also to stagger the recruitment and training for the volunteers.

This study was limited by the sample as we only interviewed volunteers from outside of London. Volunteers living closer to the venues may not have been as concerned with some of the problems identified by our sample. Furthermore, our use of self-selection sampling initially may have elicited research participants with extreme views-either negative or positive.

Our findings are situated within the context of the biggest sports mega-event. This extreme case has the advantage of highlighting the juxtaposition of size, complexity, and profile of the event; with very strong particular volunteer motivations. Clearly other studies of national, regional, and local events will find a different balance of program management and membership management. Smaller events may show further differences in management practices, such as those observed at regional events (Lockstone-Binney et al., 2015).

This article has provided insights into the better management of mega-event volunteers. Future mega-events are likely to grow both in cost to the host destination and in the size of their volunteer programs. Therefore, the importance of leveraging the event by leaving a volunteer legacy for the host community and the need to provide a positive volunteer experience is paramount.

\section{References}

Auld, C., Cuskelly, G., \& Harrington, M. (2009). Managing volunteers to enhance the legacy potential of major events. In T. Baum, T. M. Deery, C. Hanlon, L. Lockstone, \& K. Smith (Eds.), People at work in events and conventions: a research perspective (pp. 181-192). Wallingford, UK: CABI.

Bulley, D., \& Lisle, D. (2014). Re-thinking hospitality: How London welcomed the world to the 2012 Olympic and Paralympic Games. In V. Girginov (Ed.), Handbook of the London 2012 Olympic and Paralympic Game. 
Volume two: Celebrating the Games (pp. 36-49). London, UK: Routledge.

Costa, C., Chalip, L., Green, B., \& Simes, C. (2006). Reconsidering the role of training in event volunteers' satisfaction. Sport Management Review, 9, 165-182.

Coyne, B., \& Coyne, E. (2001). Getting, keeping and caring for unpaid volunteers for professional golf tournament events. Human Resource Development International, 4(2), 199-214.

Cresswell, J. (2013). Qualitative inquiry: Choosing among five approaches. Thousand Oaks, CA: Sage Publications.

Cuskelly, G., Hoye, R., \& Auld, C. (2006). Working with volunteers in sport: Theory and practice. London, UK: Routledge.

Department of Culture, Media and Sport. (2012). Beyond 2012: The London 2012 legacy story. London, UK: Author.

Department for Culture, Media \& Sport. (2013). Report 5: Post-Games evaluation meta-evaluation of the impacts and legacy of the London 2012 Olympic Games and Paralympic Games: community engagement evidence base. Retrieved from https://www.gov.uk/government/ uploads/system/uploads/attachment_data/file/224146/ Report_5_Community_Engagement_Evidence_Base_ FINAL.pdf

Dickson, T., Benson, A., \& Terwiel, A. (2014). Mega-event volunteers, similar or different? Vancouver 2010 vs London 2012. International Journal of Event and Festival Management, 5(2), 164-179.

Doherty, A. (2009). The volunteer legacy of a major sport event. Journal of Policy Research in Tourism, Leisure and Events, 1(3), 185-207.

Downward, P., \& Ralston. R. (2006). The sports development potential of sports event volunteering: Insights from the XVII Manchester Commonwealth Games. European Sports Management Quarterly, 6(4), 333-351.

Elstad, B. (2003). Continuance commitment and reasons to quit: A study of volunteers at a jazz festival. Event Management, 8, 99-108.

Fairley, S., Green, C., O’Brien, D., \& Chalip, L. (2015). Pioneer volunteers: The role identity of continuous volunteers at a sports event. Journal of Sport and Tourism, 19(3-4), 233-255.

Fairley, S., Kellett, P., \& Green, C. (2007). Volunteering abroad: Motivations for travel to volunteer at the Athens Olympic Games. Journal of Sport Management, 21, 41-57.

Giannoulakis, C., Wang, C.-H., \& Gray, D. (2009). Measuring volunteer motivation in mega-sporting events. Event Management, 11(4), 191-200.

Girginov, V. (2012). Governance of the London 2012 Olympic and Paralympic Games. In V. Girginov (Ed.), The London 2012 Olympic and Paralympic Games. Volume one: Making the Games (pp. 130-144). London, UK: Routledge.

Guest, G., Bunce, A., \& Johnson, L. (2006). How many interviews are enough? An experiment with data saturation and variability. Field Methods, 18(1), 59-82.
Hager, M., \& Brudney, J. (2004). Volunteer management practices and retention of volunteers. The Urban Institute. Retrieved from https://www.nationalservice.gov/ pdf/Management_Brief.pdf

Holmes, K., Hughes, M., Mair, J., \& Carlsen, J. (2015). Events and sustainability. London, UK: Routledge.

Holmes, K., \& Smith, K. A. (2009). Managing volunteers in tourism: Attractions, destinations and events. Oxford, UK: Elsevier.

Johnston, M., Twynam, D., \& Farrell, J. (1999). Motivation and satisfaction of event volunteers for a major youth organization. Leisure/Loisir, 24(1/2), 161-177.

Kim, M., Chelladurai, P., \& Trail, G. (2007). A model of volunteer retention in youth sport. International Journal of Sport Management, 8(3), 1-15.

Kim, M., Kim., M., \& Odio, M. (2008). Are you proud? The influence of sport and community identity and job satisfaction on pride of mega-event volunteers. Event Management, 14, 127-136.

Kodama, E., Doherty, A., \& Popovic, M. (2013). Front line insight: An autoethnography of the Vancouver 2010 volunteer expefience. European Sport Management Quarterly, 13(1), 76-93.

Koutrou, N., \& Pappous, A. (2016). Towards an Olympic volunteering legacy: Motivating volunteers to serve and remain — a case study of the London 2012 Olympic Games volunteers. Voluntary Sector Review, 7(3), 269-291.

Krueger, R. A., \& Casey, M. A. (2000). Focus groups. Thousand Oaks, CA: Sage Publications.

Lockstone-Binney, L., Holmes, K., Smith, K., Baum, T. \& Storer, C. (2015). Are all my volunteers here to help out? Clustering event volunteers by their motivations. Event Management, 19, 461-477.

Lockstone-Binney, L., Holmes, K., Smith, K., \& Shipway, R. (2016). Evaluating the volunteering infrastructure legacy of the Olympic Games: Sydney 2000 and London 2012. Lausanne, Switzerland: International Olympic Committee Olympic Studies Centre.

Lockstone-Binney, L., Holmes, K., Baum, T., \& Smith, K. (2014). Event volunteering evaluation (EVE) project: Challenging the methodological limits of event volunteering research. In K. Smith, L. Lockstone-Binney, K. Holmes, \& T. Baum. (Eds), Event volunteering: International perspectives on the event volunteering experience (pp. 167-181). London, UK: Routledge.

Lockstone, L., \& Baum, T. (2009). The public face of event volunteering at the 2006 Commonwealth Games: The media perspective. Managing Leisure, 14(1), 38-56.

Low, N., Butt, S., Ellis Paine, A., \& Davis Smith, J. (2007). Helping out: A national survey of volunteering and charitable giving. London, UK: Cabinet Office.

Meijs, L., \& Hoogstad, E. (2001). New ways of managing volunteers: Combining membership management and programme management. Voluntary Action, 3(3), 41-61.

Meijs, L., \& Karr, L. (2004). Managing volunteers in different settings: Membership management and programme management. In R. Stebbins \& M. Graham (Eds.), 
Volunteering as leisure, leisure as volunteering: An international assessment (pp. 177-196). Wallingford, UK: CABI.

Miles, M., \& Huberman, A. (1994). Qualitative data analysis: An expanded sourcebook. London, UK: Sage Publications.

Morgan, D. (1997). Focus groups as qualitative research. Thousand Oaks, CA: Sage Publications.

Musick, M., \& Wilson, J. (2008). The volunteers: A social profile. Bloomington, IN: Indiana University Press.

Neufind, M., Guntert, S., \& Wehner, T. (2013). The impact of job design on event volunteers' future engagement: Insights from the European Football Championship 2008. European Sport Management Quarterly, 13(5), 537-556.

Nichols, G. (2013) Volunteering for the Games. In V. Girginov (Ed.), The London 2012 Olympic and Paralympic Games. Volume one: Making the Games (pp. 215-224). London, UK: Routledge.

Nichols, G., \& Ralston, R. (2011). Manchester event volunteers: A legacy and a role model. University of Sheffield \& Manchester Metropolitan University. Retrieved from https://www.sheffield.ac.uk/polopoly_fs/1.227269!/file/ MEV_2012_with_cover.pdf

Nichols, G., \& Ralston, R. (2012). Lessons from the volunteering legacy of the 2002 Commonwealth Games. Urban Studies, 49(1), 165-180.

Nichols, G., \& Ralston, R. (2014). Volunteering for the Games. In V. Girginov (Ed.), Handbook of the London 2012 Olympic and Paralympic Games. Volume two: Celebrating the Games (pp. 53-70). London, UK: Routledge.

Nichols, G., \& Ralston, R. (2015). The legacy costs of delivering the 2012 Olympic and Paralympic Games through regulatory capitalism. Leisure Studies, 34(4) 389-404.

Ralston, R., Downward, P., \& Lumsdon, L. (2004). The expectations of volunteers prior to the XVII Commonwealth Games, 2002: A qualitative study. Event Management, 9(1/2), 13-26.

Ralston, R., Lumsdon, L., \& Downward, P. (2005). The third force in events tourism: Volunteers at the XVII Commonwealth Games. Journal of Sustainable Tourism, 13(5), 504-519.
Smith, K., Baum. T., Holmes, K., \& Lockstone-Binney, K. (2014). Introduction to event volunteering. In K. Smith, L. Lockstone-Binney, K. Holmes, \& T. Baum. (Eds), Event volunteering: International perspectives on the event volunteering experience (pp. 1-15). London, UK: Routledge.

Smith, K. A., \& Lockstone, L. (2009). Involving and keeping event volunteers: Management insights from cultural festivals. In T. Baum, M. Deery, C. Hanlon, L. Lockstone, \& K. Smith (Eds.), People and work in events and conventions: A research perspective (pp. 154-167). Wallingford, UK: CAB International.

Smith, K., Wolf, N., \& Lockstone-Binney, L. (2014). Volunteer experiences in the build-up to the Rugby World Cup 2011. In K. Smith, L. Lockstone-Binney, K. Holmes, \& T. Baum. (Eds), Event volunteering: International perspectives on the event volunteering experience (pp. 112125). London, UK: Routledge.

Tomazos, K., \& Luke, S. (2015). Mega-sports events volunteering: Journeys with a past, a present and a future. Voluntas, 26, 1337-1359.

Wang, C., \& Yu, X. (2014). Volunteers' motivation, satisfaction and management in large-scale events: An empirical test from the 2010 Shanghai World Expo. Voluntas, 25, 754-771.

Weed, M. (2012). London 2012 legacy strategy: Ambitions, promises and implementation plans. In V. Girginov (Ed.), The London 2012 Olympic and Paralympic Games, Volume one: Making the Games (pp. 87-98). London, UK: Routledge.

Wilks, L. (2015). A “big” legacy? Evaluating volunteers' experiences of London 2012 and beyond. In G. Poynter, V. Viehoff, \& L. Yang (Eds.), The London Olympics and urban development (pp. 270-282). London, UK: Routledge.

Williams, P., Dossa, K., \& Tompkins, L. (1995). Volunteerism and special event management: A case study of Whistler's Men's World Cup of Skiing. Festival Management and Event Tourism, 3, 83-95.

Zhuang, J., \& Girginov, V. (2012). Volunteer selection and social, human and political capital: A case study of the Beijing Olympic Games. Managing Leisure, 17, 239-256. 